\title{
Developing and Defining Migratory Practice for the Museum
}

\author{
By Emma Martin
}

Emma Martin is Head of Ethnology at National Museums Liverpool (NML). She is currently developing contemporary collecting programmes, in collaboration with colleagues in India, for NML's permanent collections. Alongside this she is undertaking research focusing on colonial collectors based in the Himalayas in the early 20th century.

\begin{abstract}
Using National Museums Liverpool (hereafter NML) as a case study, this paper will examine the challenges facing the museum as it begins to respond to the development of migratory practice. For the purpose of this paper I intend to define "migratory practice" as the movement of artists and artwork across historical definitions of practice and curatorial departments. I will be assessing how curators can challenge accepted definitions of art and ethnography by engaging with these crossings or migrations and by examining the restrictions of the current and historical classificatory and interpretative tools used in the museum.
\end{abstract}

There are several historical, ingrained factors that will make migratory practice a difficult concept for museums to embrace. Chiefly, colonialism weighs heavily on the museum conscience having played a conspicuous part in the development of the museum and specifically in the language that came to define and classify the collections found within the museum. These outdated and narrow viewpoints are still prevalent in museum today, visible in the architecture, displays and most pointedly the collections. These viewpoints, which define and separate the museum collection into "high arts" and "low arts" (Sheikh, 2006) are discussed through NML's South Asia collections, reflecting a system of museum classification and collecting that makes it difficult for the artist and the museum curator to cross between tightly controlled conceptual borders.

However, it is possible to breach these borders and a series of case studies relating to changes in collecting and interpretation practice are presented for consideration. Juxtaposing the work of rural and urban artists raises questions regarding the difficulties of using outmoded classification systems when acquiring and interpreting objects for the museum, and mechanisms for approaching work that isn't exclusively "fine art" or "ethnography" are discussed. New collaborative ways of collecting and commissioning are described, suggesting ways in which museum curators can bring global perspectives to the historical and colonially influenced collections and displays.

The paper concludes by offering alternative curatorial interpretation devices, reversing the accepted Western display techniques of "ethnographic" exhibits and "fine art" galleries. 


\section{Introduction}

Museum displays and collections can act as sites of remembrance for changing critical theories and approaches to curatorial practice. Throughout the 20th century, and into the 21st century, curatorial thinking has been influenced by dialogues with the discipline of anthropology. The question arises then; will the museum respond to the development of "migratory practice" and more specifically how are collaborations between the disciplines of contemporary art and anthropology challenging museum curatorial practice?

I will consider the significance and the tangible results of these collaborations and the challenges facing the curator responsible for acquiring and classifying both "art' and "ethnographic" objects for museum collections. I hope to raise issues surrounding the concept of the "border crossing" as discussed by Schneider \& Wright (2006) and to examine how the traditional Western museum taxonomies of "art" and "anthropology" become contested reference points when practitioners will not or do not wish to conform to a particular set of museum criteria. My discussion will establish a predominately South Asian context drawing on my experiences of curating Asian, and particularly South Asian collections, for over a decade. As a country subjected to Imperial rule, India and its arts and crafts underwent a process of colonial classification in the mid 19th century as a result of the development of world exhibitions, the most famous of these being the Great Exhibition of All Nations (more commonly known as the Crystal Palace Exhibition) held in London in 1851 (Dadi, 2006). The classificatory systems that were put in place to categorise objects for the great exhibitions were a cultural manifestation of emerging colonial theories. Discussed and published by colonial officers stationed in South Asia in the 19th century these systems helped to categorise and contain the enormous diversity of many colonised peoples and their material culture. This categorisation of material culture, and more specifically objects, formed the backbone of later Western art historical narratives, and by extension the hierarchies of Western museums and their classification systems. It is my intention to explore one aspect of that history here and its impact on current patterns of British museum collecting.

\section{The Colonial Hangover}

I begin by setting out an historical framework for the current difficulties faced by museums, using the permanent museum collection as my focus. I use my own institution, National Museums Liverpool (NML), ${ }^{1}$ as an example, in an attempt

1 NML is the only UK national museum based solely outside of London. Its collections are diverse ranging from slavery to space sciences, ethnography to maritime history and from fine arts to zoology. 
to shed some light on the historical reasoning for the segregation of collections and the enduring colonial connotations inherited by the curator working in a post colonial world.

The creation of NML was closely tied to the British Empire with its collections and buildings reflecting the imperial achievements of Britain and specifically the achievements of Liverpool, as the second city of the Empire. The city's wealth generated by the 19th century maritime trade is revealed through the objects donated to the city's museums by Liverpool's sea captains, merchants and colonial officers. This Imperial celebration was not just confined to the museum's objects and buildings, but filtered through every aspect of the organization, permeating the classification systems used to order and define a diverse range of collections that reflected the city's global reach.

This definition and separation of disciplines, which laid the foundations for the collecting and cataloguing processes adopted by NML, are well over 150 years old, but shockingly they still govern how and what we collect today. The classification systems set down in the 19th century facilitated the partition of art and craft practices from the west and what Gulammohammed Sheikh describes as 'art and craft practices on the periphery of western understanding i.e. the rest of the world' (2006). This created the assumption that Western art or the "high arts" was solely concerned with the urban educated practices of painting and sculpture, and the urban industrial arts including textiles, ceramics, glass and metalwork, while the anthropological pursuit of ethnography focussed on the periphery, or the "low arts", and what Sheikh defines as the, "rural/tribal object defined as 'pre modern' or 'traditional'". This labelling of place and practice illustrates a hierarchical classification of objects that is alive and well in today's museum and still holds great influence over the curating, collecting and displaying of objects at NML.

\section{Display Segregation}

This is physically born out in NML's architecture, displays and exhibitions. NML's main suite of museums and galleries are to be found on William Brown Street, a sloping site picked by Liverpool's 19th century philanthropists. There should be no prizes for guessing that the Walker Art Gallery sits with pride of place at the pinnacle of the hill, while the museum of natural sciences (known as World Museum), which incorporates Zoology, Ethnology and Egyptology, resides at the bottom. Could this positioning of gallery and museum have been intentional, reflecting the perceived value of the collections housed inside? The two museums employ distinct display techniques. Once inside, the Western history of Fine Arts and Decorative arts displayed at the Walker Art Gallery focuses on key movements and prized individual artists who fit into the eurocentric view of the art world (Fig 1). 
craft + design enquiry

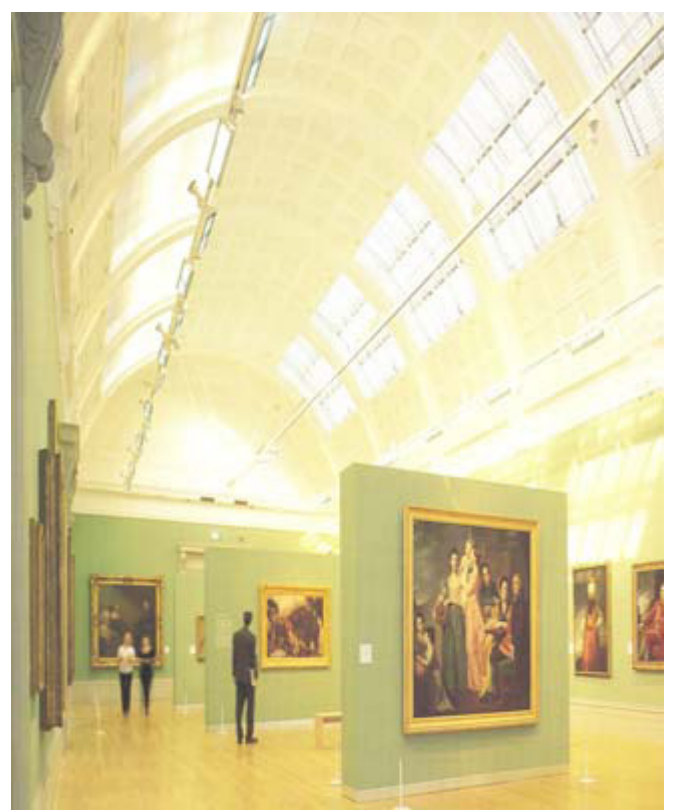

Fig. 1. View of temporary exhibition space, Walker Art Gallery Image courtesy of National Museums Liverpool.

While the World Cultures gallery at World Museum geographically focuses on the carvings, textiles, costume and domestic items that colonial officers sought to collect as a definitive representation of specific cultures colonised during Empire (Fig 2).

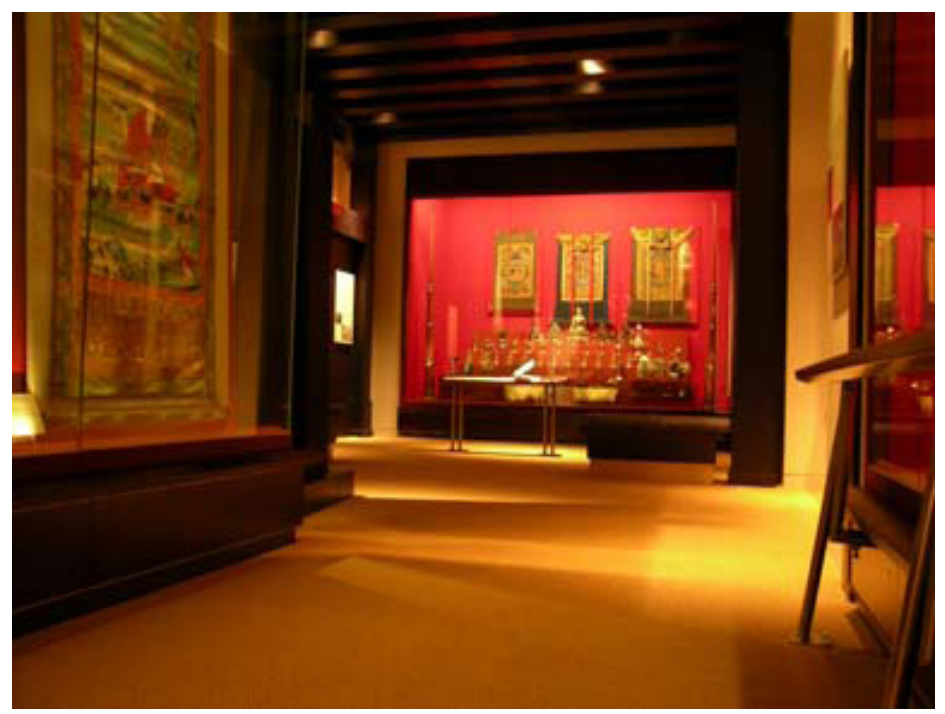

Fig. 2. View of Buddhist display, World Museum Image courtesy of National Museums Liverpool. 
In recent years the concerns of the collector and their reasons for collecting have formed an important part of anthropological - and by extension - museum collection- based research, presenting many museums and their audiences with in-depth knowledge regarding the collectors of ethnographic objects. While the museum curator's knowledge of the colonial context is widened, often the knowledge associated with the maker's identity, unrecorded by those same colonial collectors, remains hidden. The World Museum displays compound this concept of the anonymous, timeless maker as they place the visitor within a 'time limbo', as at a glance it is unclear if these displays represent the past or the present. There is little sense of a historical or a contemporary context and where there is a focus on named individuals they invariably are the collector of the object rather than the maker.

\section{Departmental Structures}

Away from the gallery displays, the colonial construct remains just as strong behind the scenes. Taking the Fine Art department as an example, its curators have responsibility for aspects of the fine art canon, including British Art, European Art and Works on Paper, Ethnology curators are responsible for Asia, Africa, Oceania and The Americas respectively, all enormously complex and layered continents that are impossible for one curator to ever properly research or represent. The demand for greater numbers of specialist art curators in comparison to the Ethnology department is not borne out by the size or importance of the collections with the Asia collection, for example, containing almost 20,000 objects, while the Fine Art department holds around 10,000 objects. This imbalance in resources and specialist staff only reiterates the peripheral importance bestowed on the ethnographic collections both in the formative years of the organisation and in its current guise.

The structures put in place have without a doubt affected NML's collecting processes and also the types of practice collected. The fine arts remain in the tight parameters of painting and sculpture, while the decorative arts focuses on ceramics, textiles, glass and metalwork, the majority of which come from the urban art schools or industrialised urban practice. In contrast the ethnography collections predominately represent the rural, hereditary, 'pre-modern' traditional crafts. What the museum classification system promotes, in this case, is the notion that only the urban educated artist can be included as a modern or contemporary artist within the fine art discipline, while the rural artist must stay within the boundaries of the pre- modern or traditional collective, confined to the categorisation of ethnographic.

\section{Sonabai Rajawar: Defying Classification}

Curatorial staff at NML are increasingly pushing against these classifying restraints and the dichotomy of the aesthetic/anthropological approach as described by Clifford (1988), which places art works by individuals strictly 
within the art exhibition, while the collective (anonymous) work of cultures are represented through anthropology displays. Indian curator Dr. Joytindra Jain takes this concept a step further in his essay for the exhibition catalogue Other Masters: Five Contemporary Folk and Tribal Artists of India (1998) when he argues that the anonymous, unchanging rural artist has become the counter to the ingenuity and innovations of the western artist and that due to market forces and the increasing interests in Indian handicrafts in the second half of the 20th century, the rural artist has been forced to remain within a timeless tradition. If the rural artist becomes an innovator, responding to the contemporary environment, there is the sense that the authenticity of the tradition is lost and the artist is therefore compromising an unchanging practice. As Jain rightly points out, this concept of the unchanging rural artist is a colonial construct. This need to preserve and represent became an important aspect of salvage ethnography during the late 19th and early 20th centuries, at a formative time in the development of anthropology as an academic discipline. By working with innovative rural artists museum curators do have the opportunity to unpick many of the presumptions that underpin these notions of the unchanging traditional artist. In 2005 NML had the opportunity to commission work for the permanent collections, from one such artist. Sonabai Rajawar (ca.1931 - 2007) was a renowned sculptor from Chattisgarh state in Central India (Fig 3).

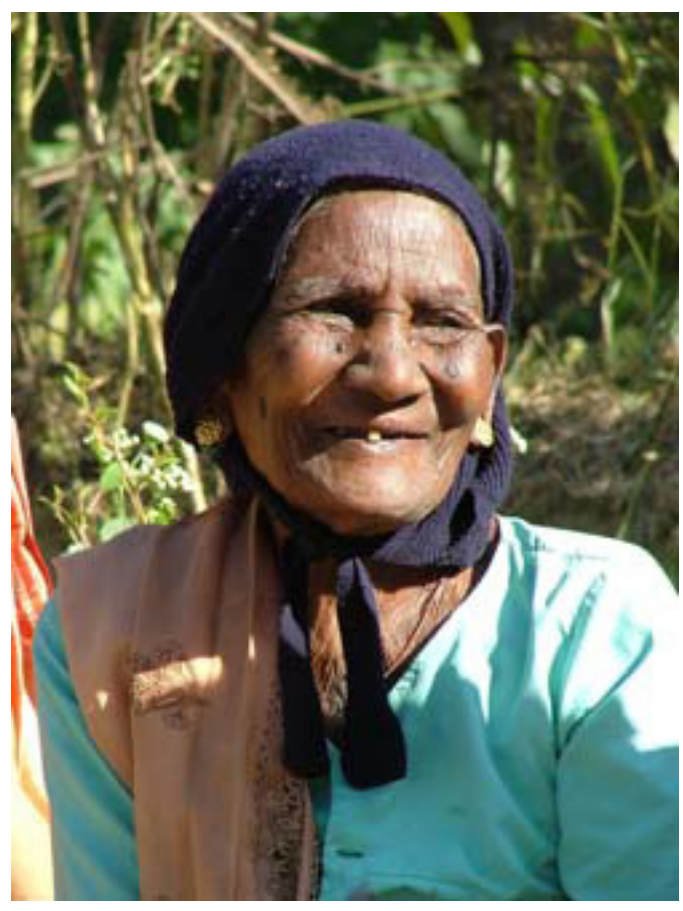

Fig. 3. Sonabai Rajawar 2005.

Photograph by Nick Gordon 
Championed by Jain, Rajawar was celebrated in Other Masters: Five Contemporary Folk and Tribal Artists of India as exemplifying 'artistic innovation and expression' (1998). Rajawar sculpted vivid mythical and pastoral clay relief panels and figures for approximately sixty years, until her death in August 2007 (Fig 4).

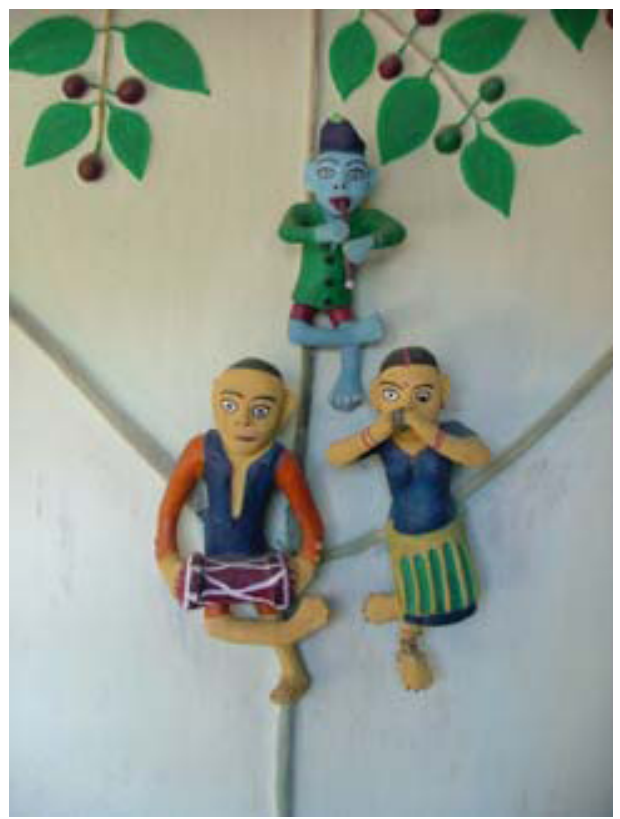

Fig. 4. Sonabai Rajawar, 2003, Chherta Festival with Krishna Ca, (Clay, cow dung, straw, pigment),.

Photograph by Nick Gordon

She was married at 15 to a widower and lived in isolation with her husband in their home on the edge of the village of Puhputra, in Sarguja district. It is not the practice of Rajawar's community to place women in isolation, so her situation although familiar to some women in India was exceptional for Rajawar and her community.

As a result, during the early years of her marriage she had no female contact, only that of her son and husband. At this time she began creating clay bas relief sculptures populating her home with, as she described them, 'friends' placing the young Rajawar in bustling dances of harvest and in scenes from the Hindu epics.

Rajawar's work was inspired by the important festival known as chherta, which is celebrated on the full-moon day of pus (December). Chherta celebrates the end of a successful harvest and throughout the Sarguja district all Rajawar houses 
are repaired, ${ }^{2}$ re-painted and adorned with elaborate wall-paintings and clay relief work, with great rivalries between the women, as each strives to create the most beautiful decoration (Fig 5) (Jain: 1998).

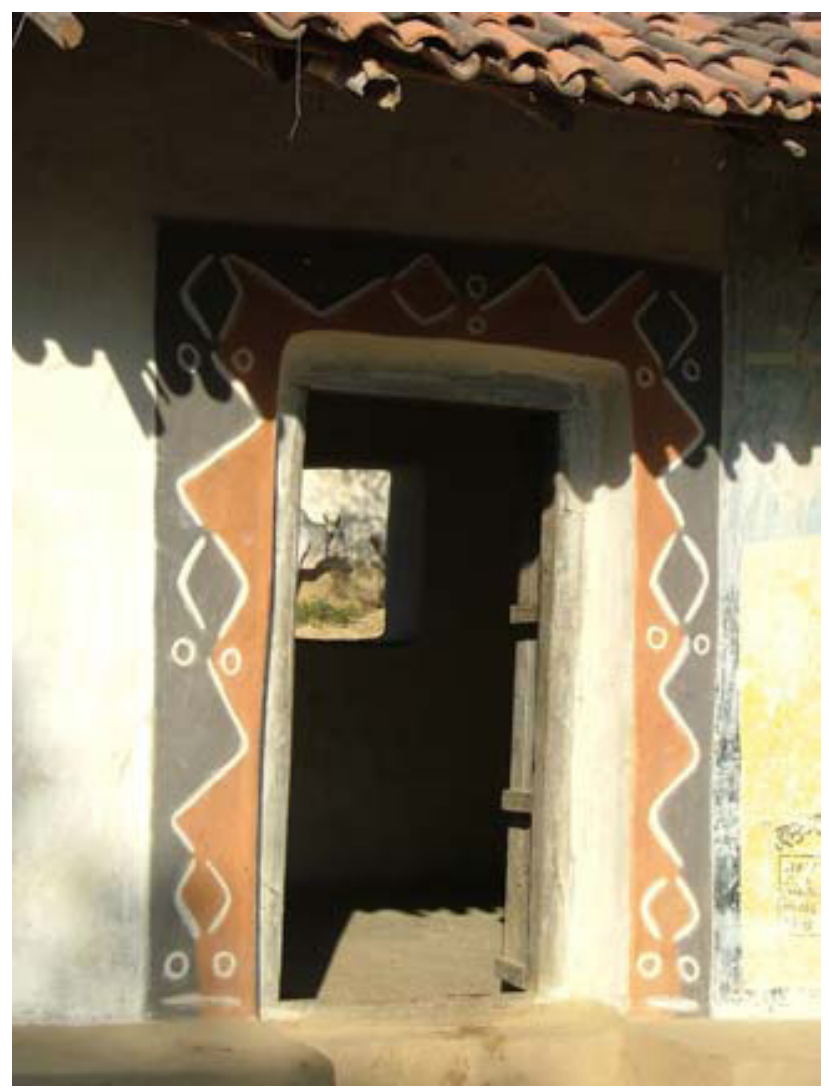

Fig. 5. 2005, decorated doorway, Puhputra, Chhattisgarh, India.

Photographer Nick Gordon

Rajawar's circumstances provided her with the inspiration and the impetus to incorporate new elements into a practice that had been locally abstract and minimal in its use of colour and design. She introduced new techniques of construction, new motifs personally connected to her life experiences and increasingly she devised new colour palettes, which included chemically based pigments. Rajawar's personal situation eventually changed, allowing her to have contact with other women and village members, which in turn brought her work to a wider local audience and finally to the attention of the Bharat Bhavan, an innovative centre for contemporary rural art in Madhya Pradesh. This wider contact resulted in museum exhibitions and installations, national craft awards and the development of Government funded initiatives that allowed younger members, including male sculptors, of the local community to train with Rajawar

2 The surname denotes affiliation to the farming community. 
and develop their own skills and narrative themes. While the practice began as a response to one woman's personal situation, the younger generation of sculptors are increasingly travelling throughout the state and in some cases nationally and internationally, drawing inspiration from the environments and practices they encounter.

\section{Rajawar's Legacy}

Atma Das Manikpuri, a sculptor from the Sarguja area was one of Rajawar's apprentices (Fig 6).

As a young man he had thought of training at the regional art school and in preparation he had used the course reading list to familiarise himself with the work of early 20th century European painters, particularly the Cubist work of Picasso and Matisse. Circumstances prevented Manikpuri from undertaking his art studies, but a profile on Rajawar in the local newspaper provided a new focus for his creativity.

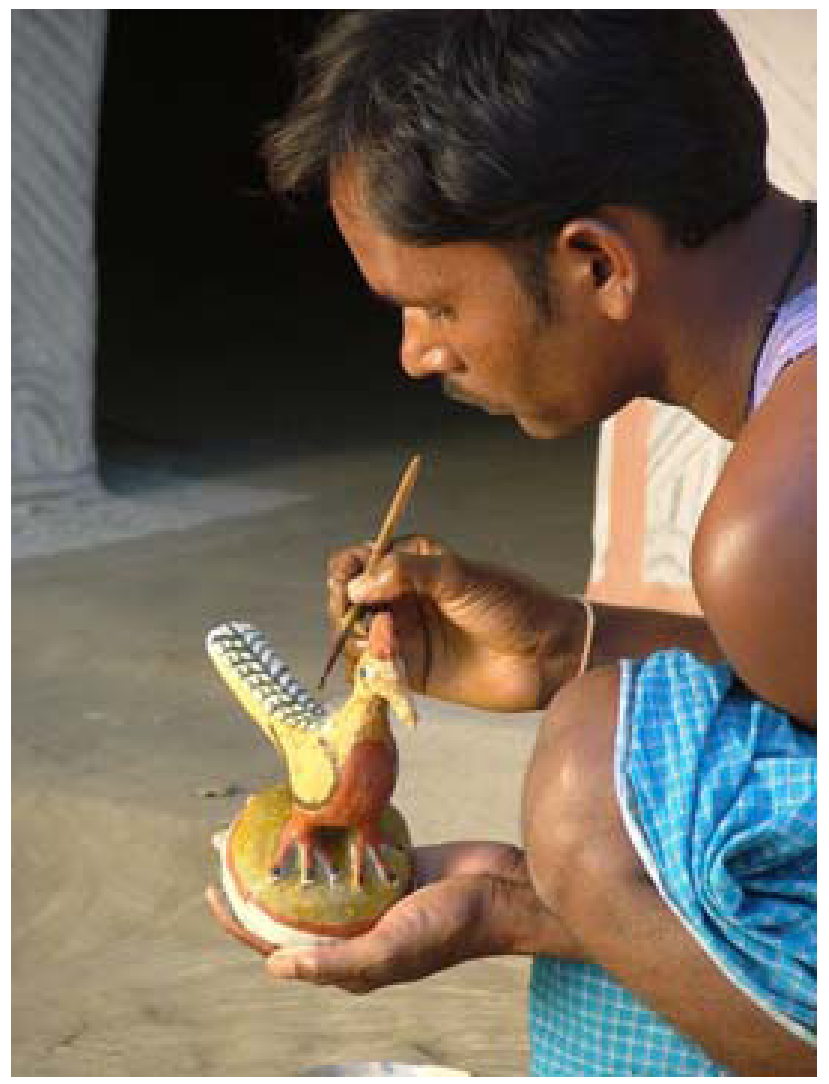

Fig. 6. 2005, Atma Das Manikpuri.

Photographer Nick Gordon 
While he initially created copies of Rajawar's clay relief, he was eventually able to take part in the training scheme spending time with Rajawar and studying her skills. While developing his own skills he also began to develop his own narratives, in some cases following Rajawar's lead, creating sculptures with a local context, such as local festivals and agricultural scenes, while in other pieces he drew on his own experiences using the Cubist painters he had familiarized himself with in preparation for his art school studies as inspiration (Fig 7).

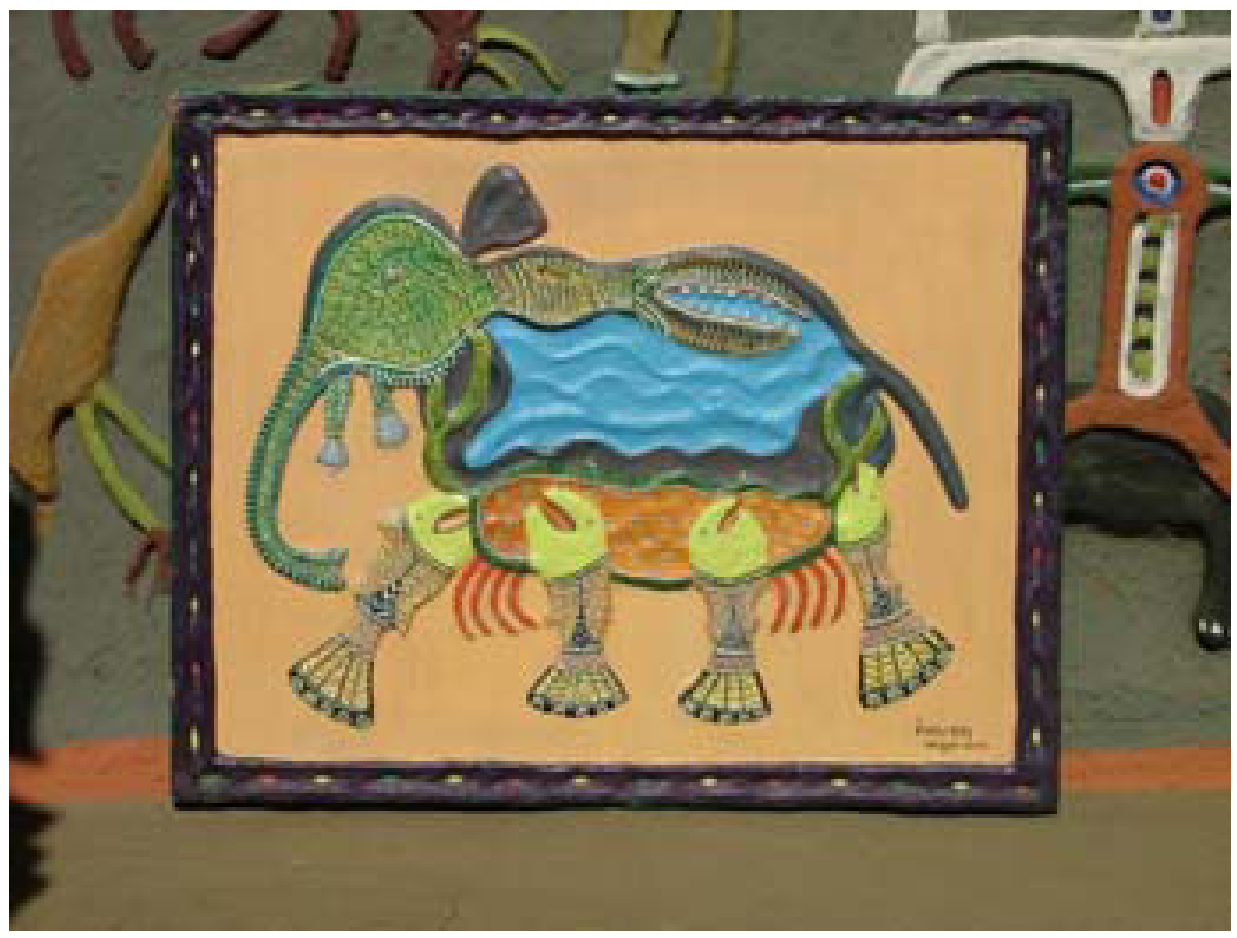

Fig. 7. 2005, Atma Das Manikpuri Elephant of Many Parts (Clay, cow dung, straw, pigment).

Photographer Nick Gordon

\section{Diversity in Contemporary Practice}

The practice developed by Rajawar and continued by the younger generation of sculptors shows that the contemporary and the traditional do not have to be uneasy bedfellows and that the use of traditional practice should not imply an anonymous, mechanical, uninspiring and unchanging practice. As Clifford \& Marcus (1986) state modernity is a complex overlaying of many traditions and cultural traces and it is useful to bear this in mind, rather than falling back on the simplistic oppositions between traditional and contemporary. Rajawar's work is reflective of a specific place and set of conditions and as a result it is a striking contrast to the contemporary work created by Western art-school 
trained artists, supported by the Western art markets and by extension art museums. However, this contrast, this 'otherness', should not automatically classify Rajawar's work as ethnographic, simply because it does not fit neatly into the western paradigm. Thomas McEvilley highlights this when he states, 'When one culture regards the objects of another, those objects are instantly incorporated into an alien framework, they are helplessly interpreted through some habit of thought different from the habit of their makers' (1992). This is particularly pertinent in the museum context, as the placing of Rajawar's work into a gallery space directs the visitor and curator alike to reach for the familiar language of Western art history to interpret this new and unfamiliar work.

Challenging these internal and institutional interpretations is not easy and it would be foolish to suggest otherwise. There is undoubtedly a need to create new forms of 'intellectual and creative currencies tradeable across frontiers and cultures' (Rangasamy, 2006), but this is an enormous undertaking when an organisation's language and identity are tied to ingrained colonial thought processes. However, small steps can be made and there are mechanisms that can be put in place to question these assumptions and preconceptions and it is to these that I now turn.

\section{Contemporary Collecting}

The commissioning and collecting of panels and sculptures from Rajawar in 2005 was the first example in nearly 20 years of contemporary collecting by NML from the Indian sub-continent. My visit to her home and the acquiring of specifically commissioned pieces set in motion the redefining of the Ethnology department's collecting policy and indeed future collecting programmes at NML.

One of the first initiatives in the Ethnology department following the visit to Rajawar's home has been to develop partnerships with other organisations creating dual curatorial roles between external South Asian organisations and NML. Developing international partnerships is high on NML's agenda and although joint exhibition and events programming are becoming ever more part of the museum's practice, the actual building of permanent collections had not, until now, been part of that collaborative process.

During the 2005 International Folk Art Conference held in Chandigarh, North India, I met Minhazz Majumdar. Majumdar is a writer, promoter and co-director of The Earth and Grass Workshop, a crafts development agency that works with urban and rural artists across central and eastern India. Even though our meeting was brief it was clear that we had much in common, particularly our desire to bring greater parity and wider attention to contemporary Indian rural arts and artists. Over the course of 2006 we discussed ways in which new perspectives could be brought to NML's South Asia collection, which would give it a greater relevance for today's museum visitor. This was not a straightforward task, as the historical collection largely consists of arms and armour, much of it collected, or bagged as official loot, following the various battles that took 
place across the Indian sub-continent in the 19th century. As the collection was so biased towards colonial encounters, and indeed the collection has a predominately masculine edge, it was clear that we needed a fresh approach. Majumdar and I decided that we needed to bring a balance to the collection, with a future focus centred on women, who are almost invisible in the current collection, and additionally on the equally under-represented rural artist. Towards the end of 2006 we successfully applied for funding, from which we developed a three-year pilot collecting project called Collecting Contemporary India. The aim of the project is to collect a body of work from two artists, per year, for a period of three years, allowing The Earth and Grass Workshop and NML to develop relationships with specific artists, track developments in their work and create a visual and oral record of their working practices during the year. The need to move away from an ahistorical presentation was a pressing issue, so it was agreed that we would additionally collect works from emerging artists working closely with or in a similar style to our chosen artist, and likewise, if the opportunity arose, we would collect from artists who had heavily influenced our chosen artist.

To challenge NML's collecting practices the final choice of artists has been handed over to The Earth and Grass Workshop, creating another dimension to the idea of migratory practice, with the curatorial role being shared with an external organisation that has not previously been involved in the curatorial process. Both Majumdar and I felt this was an important step to take, which would enable The Earth and Grass Workshop to choose artists who might not have been considered by a western curator.

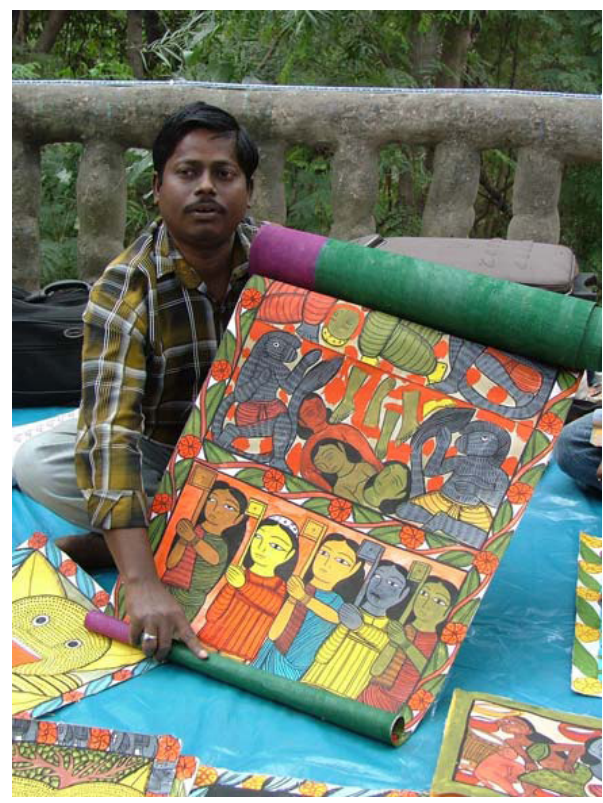

Fig. .8. 2005, Montu Chitrakar,

Courtesy of Minhazz Majumdar 
In this, the first year of the project we have worked with two very different artists, Montu Chitrakar, a scroll painter and storyteller from Bengal (Fig 8) and Puspha Kumari, a painter from Mithila, Bihar, an area renowned for women's wall and floor painting (Fig 9).

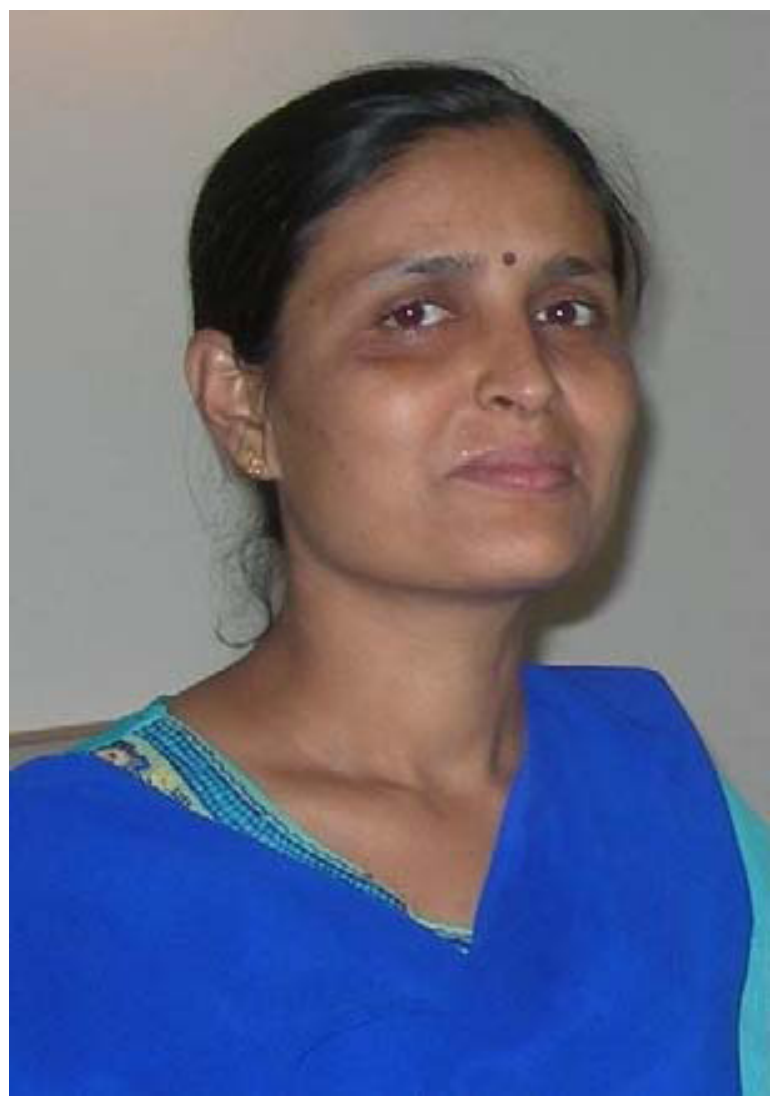

Fig. 9. 2007, Pushpa Kumari.

Courtesy of Minhazz Majumdar

I would briefly like to share with you two of the newly commissioned pieces, from Kumari. Kumari's response to The Earth and Grass Workshop's brief has been to create a series of pieces, including a triptych, on the place and role of women in Indian society. The Phases of the Moon discusses the central role of women in day- to-day life and the presence of the feminine throughout the cosmos, represented here by the lunar cycle (Fig 10). 


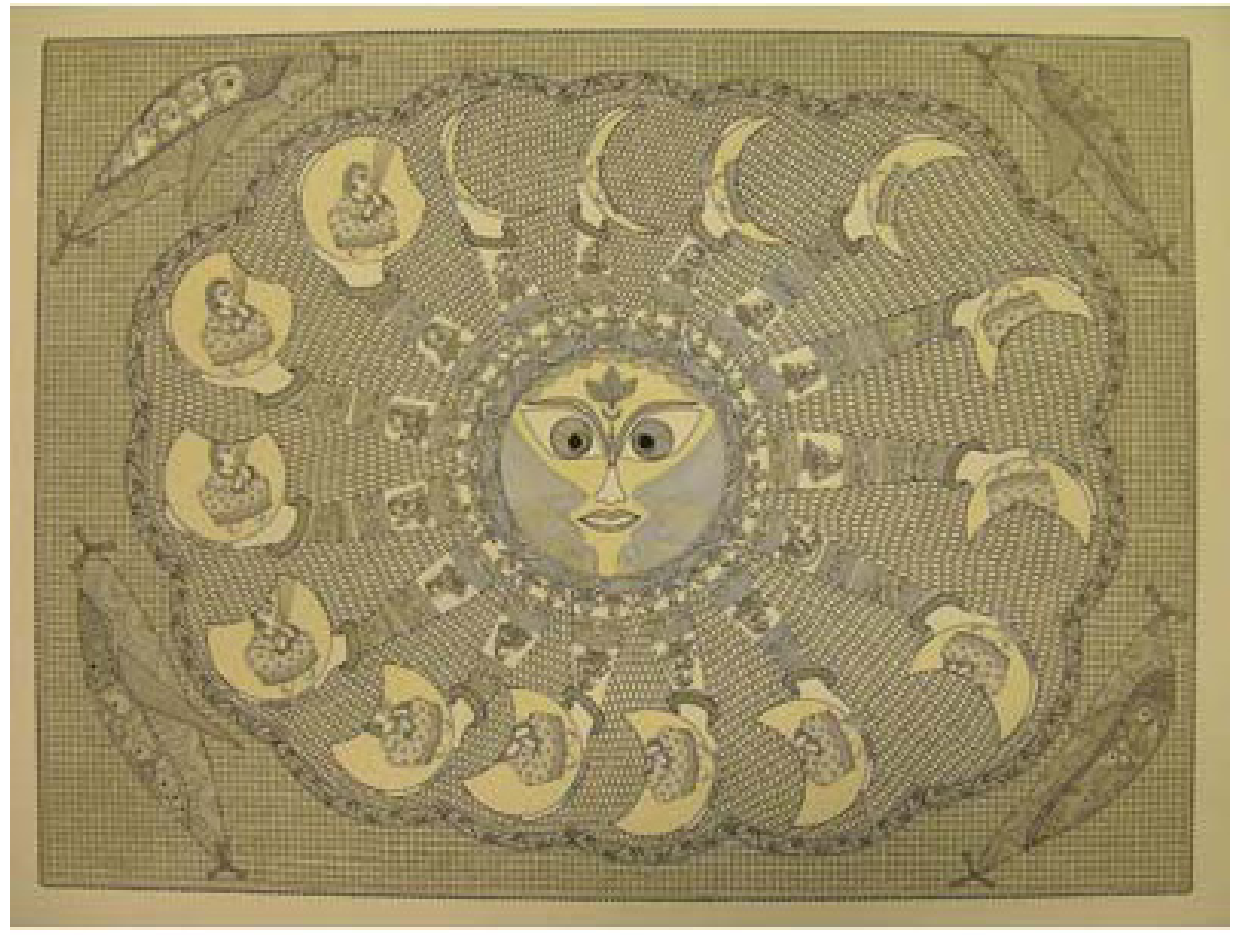

Fig. 10. 2007, Pushpa Kumari Phases of the Moon (Paper, ink).

Courtesy of National Museums Liverpool.

This theme is continued in a second piece entitled Which Came Before - The Seed or the Plant? which focuses on the female life-force and by extension the feminine power (Shakti) that man is impotent without (Fig 11).

Kumari's artistic path will resonate with many artists who have encountered difficulties in the early years of their careers, particularly in relation to the tension between making a living and maintaining one's artistic integrity. Due to the popularity of Mithila painting as a cheap tourist souvenir, artistic innovation, as found in Kumari's work, was difficult to place within the market and as a result floundered due to a lack of knowledgeable buyers. Kumari had the difficult choice to make between making a living, reproducing 'traditional' paintings for the tourist market, and creating innovative pieces that had still to find a market. Kumari did have to resort to reproducing popular Mithila paintings early on in her career, but has now attracted a group of international buyers and patrons, which has enabled her to develop her own themes and style. 


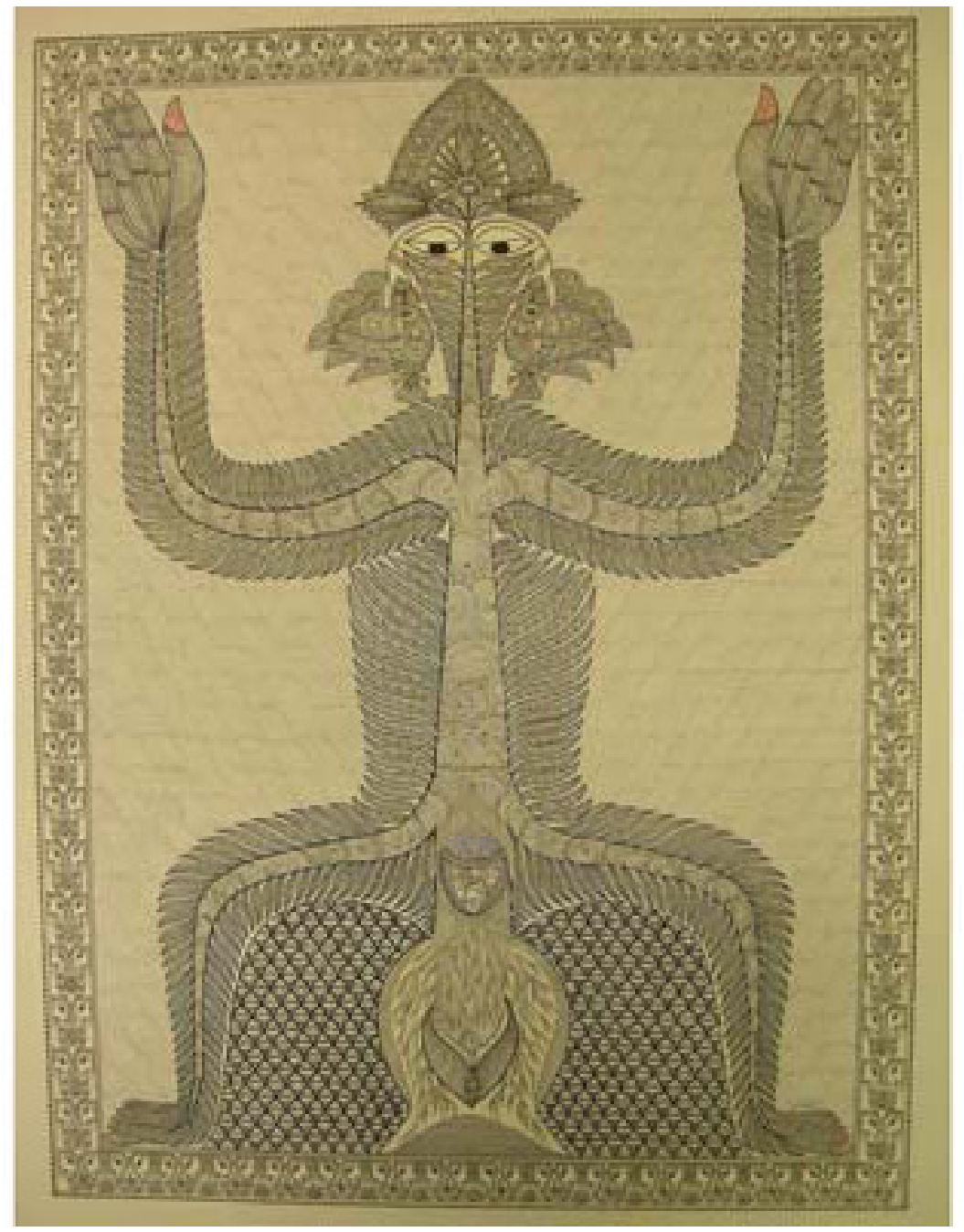

Fig. 11. 2007, Pushpa Kumari Which Came Before - The Seed or the Plant? (Paper, ink).

Courtesy of National Museums Liverpool.

This three-year project is just the first stage in a long process. It is hoped that the success of the project will allow The Earth and Grass Workshop and NML to turn their partnership into a long-term venture, allowing the partners to return to the initial artists chosen for this project and again commission new works from them over an extended period, allowing for the documentation of changes and influences in their practice throughout their careers. While this project has been very much based within the Ethnology department, there has been growing interest from the Fine Art department and discussions are underway to host an exhibition of the new works in the Walker Art Gallery at the end of the three-year 
project. This would be an important first step to creating a more holistic NML collecting and display policy, which would see works displayed outside of the accepted art gallery/ethnographic exhibit paradigm.

\section{Adeela Suleman - Migrating Artist}

While the project described above clearly focuses on the rural contemporary artist, NML is also developing proposals that will allow both the ethnography and fine art curators to work together to develop a series of residency programmes for urban based artists from Pakistan. Of particular interest is Adeela Suleman, a Karachi- based artist who challenges the museum classificatory system and the dichotomy between "high art" and "low art", referred to at the beginning of this paper. Her practice poses something of a conundrum for NML when considering how her work would fit into outdated collection areas.

Working with artists like Suleman, will be an important step for NML's curators, challenging preconceptions regarding the appropriateness of certain objects and installations for specific collections. As long as accepted hierarchies of high art, low art and at the very bottom, ethnography, remain, it makes significant changes to institutional thinking incredibly difficult to implement. However, ignoring artists who are challenging these systems is not an option and indeed artists like Suleman can play a significant role in helping to re- or de-classify museum collections. Working with artists, like Suleman, can potentially make collections and curators more receptive to those practitioners travelling across what had previously been tightly prescribed classificatory borders, allowing museums to respond more effectively to the development of migratory practice.

Suleman's work is inspired by her personal experiences of living and working in Pakistan and through her practice she looks to understand and comment on the realities of Pakistani culture and politics. In 2002 she created, for the 2nd Fukuoka Triennale, an installation piece entitled Salma, Sitara and Sisters Motorcycle Workshop (Fig 12).

This work deals with the issues of nationality, class and gender through the common sight of women travelling on a motorcycle. This everyday activity takes place in a unique way in Pakistan. Women sit on the motorcycle in a side-saddle position with their husband driving; while both help each other to balance themselves and more often than not their children. This everyday occurrence gives an insight into the gender relations, exploring how women sit on the motorcycle, and class relations, particularly the fact that motorcycles are predominately used by the lower classes and lower middle classes; and finally comments on the uniqueness of the Pakistani context.

Suleman takes on the male dominated space of the truck workshop creating a showcase of accessories and implements for the female motorcycle passenger. Offering a full service of custom-designed pieces Suleman creates fantasy solutions for circumventing the gender imbalances placed on the woman as she rides in a sidesaddle position (Fig 13). 


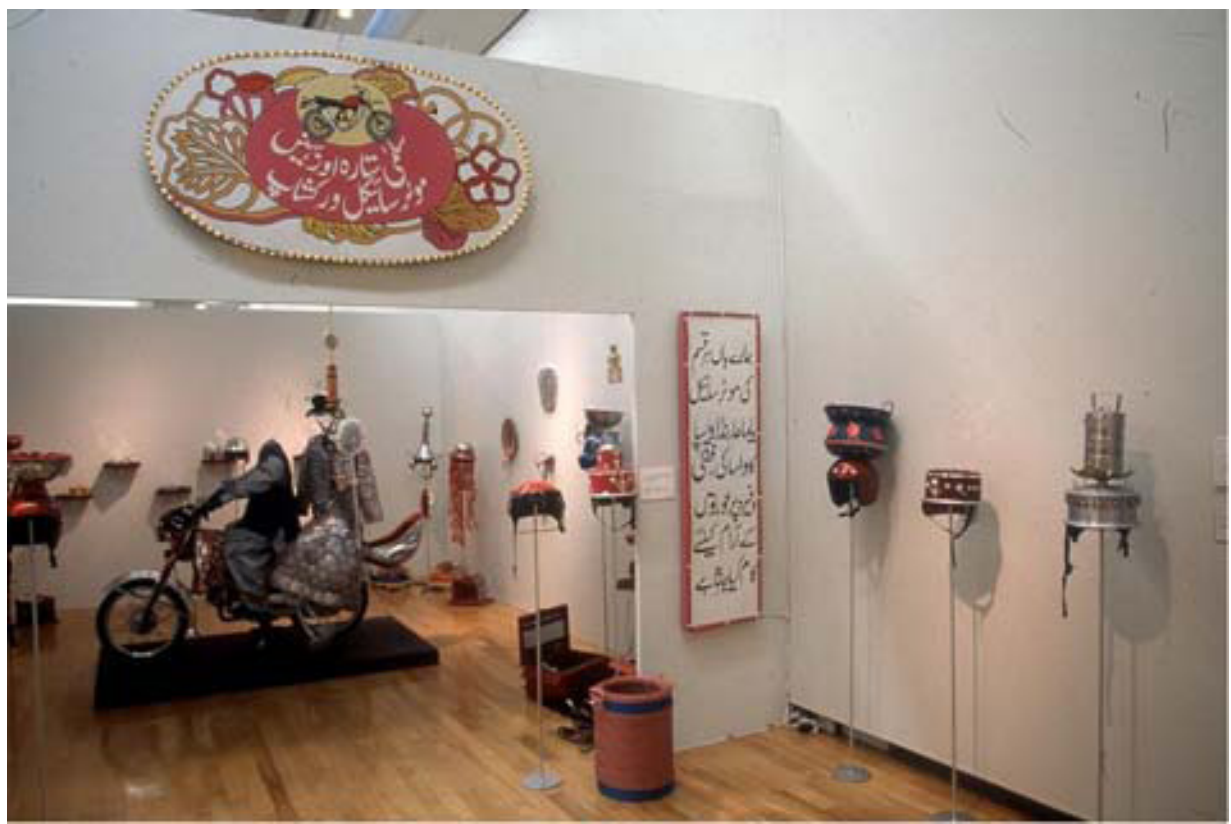

Fig. 12. 2002, Adeela Suleman, Salma, Sitara and Sisters - Motorcycle Workshop (Mixed media).

Courtesy of Adeela Suleman.

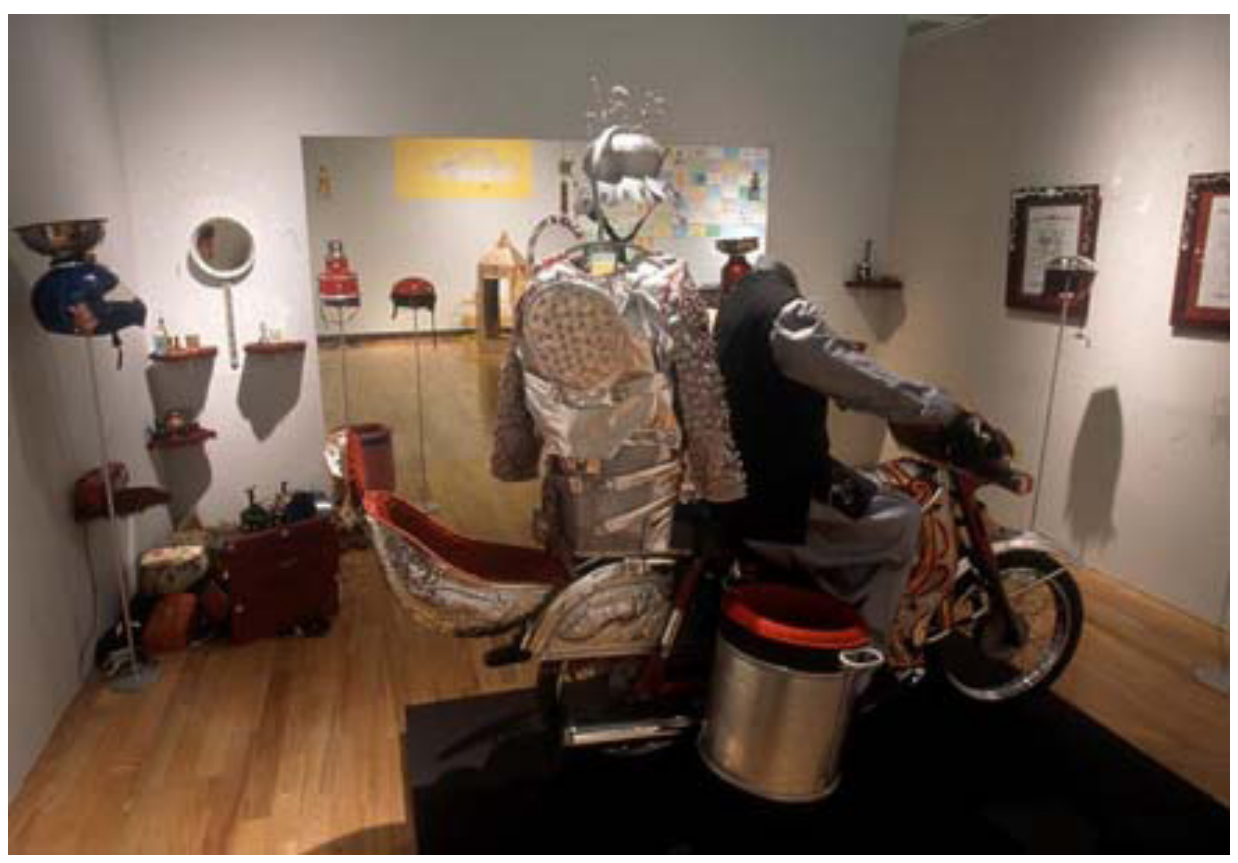

Fig. 13. 2002, Adeela Suleman, Salma, Sitara and Sisters - Motorcycle Workshop (detail), (Mixed media). 
Her work reflects a society where economic, social and gender inequalities are an everyday fact, but by building a parallel universe, she creates a situation tailored solely to women. Suleman incorporates found or everyday objects into her work, whilst also incorporating the skills and techniques of the craftsman working in an urban environment (Fig 14).

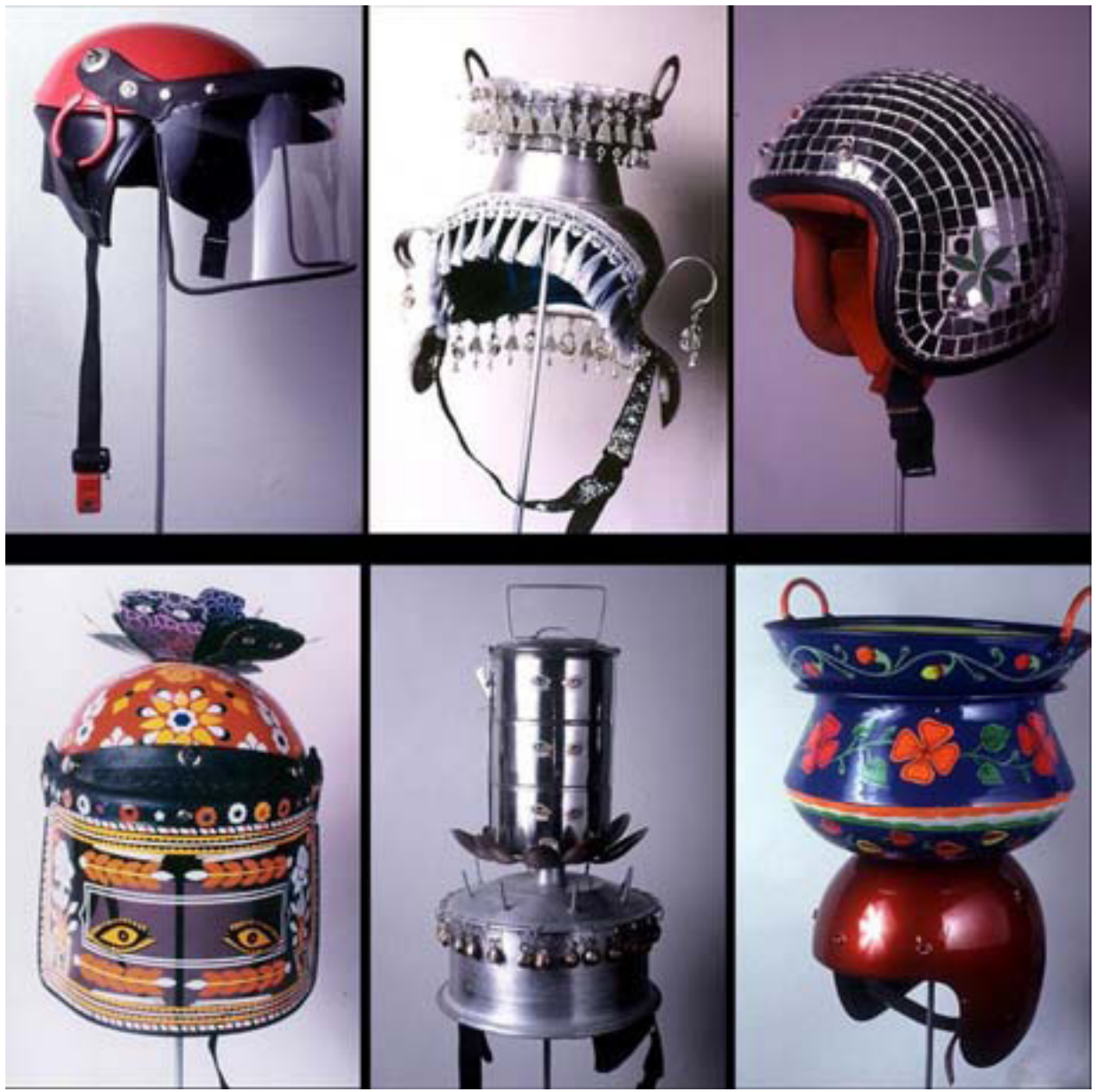

Fig. 14. 2002, Adeela Suleman Salma, Sitara and Sisters - Motorcycle Workshop (Helmet detail), (Mixed media).

Courtesy of Adeela Suleman.

When discussing this piece Suleman recalls the laughter that rang out through the real motorcycle workshop that she worked with when she went to discuss her ideas with the men who worked there (Fig 15). 


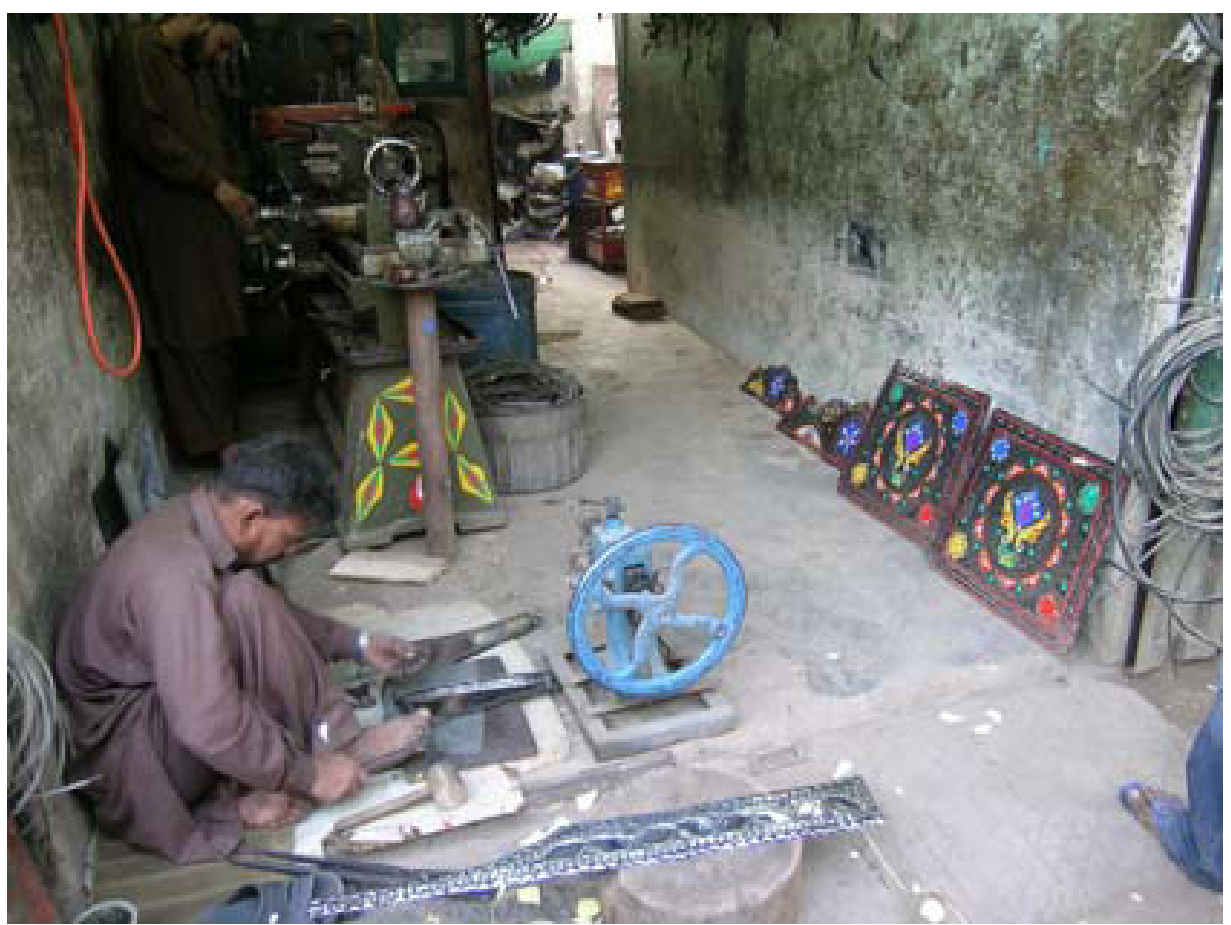

Fig. 15. 2005, Truck decoration workshop, Karachi, Pakistan.

Photograph by Emma Martin.

While they initially found her ideas and intentions somewhat bizarre, a genuine rapport developed as she began to work closely with the men to produce, some extremely practical, but simultaneously, utterly fanciful pieces reflecting the visual language of her environment. With this installation Suleman addresses the complex nature and the practicalities of living in urban Pakistan. She examines the male- female relationship on the motorcycle, highlighting the closeness required of the situation and its variance from the social norms of Pakistani society. As Salima Hashmi comments 'Suleman's work crosses many borders between fantasy and function, industrial production and craft and between the gender roles' (2001).

\section{Conclusion}

In the 21st century people and objects are less defined by practice and place than previously. The lives of individuals span many continents both virtually and physically, gathering influences and concepts along the way. This fluidity is increasingly represented in contemporary objects, raising urgent questions for museums regarding established collecting practices. Possibly most pressing 
of all is how to deal with colonial legacies inherent in collecting policies and classificatory systems? Museums need to engage with new systems which can better articulate the changes taking place across the world in the 21st century.

I return to Rangasamy's (2006) call for new intellectual and creative currencies, but in reality how would this manifest itself? As Rangasamy implies, it would be impossible to find one overarching language that could be used to interpret museum collections. Of course, not all museum objects can or should be classified as solely 'art' or 'ethnographic', and geographically speaking it has become increasingly difficult to classify an object as strictly Indian or British for example. However at a very practical level the interpretative methods employed by the museum curator are a good starting point for shifting perceptions. As museums look to globalise their permanent collections and exhibition programmes, there is also a need to globalise the curatorial perspectives. Major museum exhibitions, including the multi-venue ArtSouthAsia programme held in $2002,{ }^{3}$ are increasingly asking international curators and artists to curate museum exhibitions, bringing new insights to those collections and challenging the accepted status of certain aspects of the collections held by the host organisation.

When this paper was originally presented in 2006 , it was suggested to me that there should be an opportunity for curators with specialist ethnographic or fine art knowledge to exhibit objects from the other's collection area. ${ }^{4}$ The ethnographer would employ anthropological techniques to display a group of Rembrandts, discussing the cultural traditions of this particular type of painter, including trade and exchange, kinship and ritual festivals with their individuality as a painter considered unimportant. Objects from the ethnographic collections would be displayed with minimal context, the name of the object, and most importantly, of the artist enough to elicit a knowing nod of the head from the visitor. While I have yet to see an ethnographic exhibit of Flemish painters, there have been attempts in India to display the works of rural artists using a fine art mode of display. Bharat Bhavan, an arts centre in Bhopal, which has a remit for collecting contemporary rural arts has presented a large number of rural artists in 'one man shows'. The founder of the centre, Jagdish Swaminathan (1928-1994), was an artist, but more importantly, a promoter of rural arts and an advocate of rural artists and their right to be accepted within the contemporary art world. He was instrumental in displaying the work of rural artists in individual shows and interpreting their work without an ethnographic context. This is still unusual almost 20 years after Swaminathan first proposed this curatorial practice.

It is clear from the few examples that I have presented in this paper that the effects of 'border crossings' will increasingly have implications for the development of museum curatorial practice. With Western constructed value

3 SHISHA, a South Asia arts agency based in Manchester, UK developed, in collaboration with South Asian curators, a multi-venue programme of exhibitions entitled ArtSouthAsia.

4 Many thanks to Dr. Sharon Macdonald for suggesting this idea. 
systems continuing to form the basis for the language used to define and separate practice and place, a solution to these issues is clearly some way off. However, greater levels of exchange between artists, curators and collections can affect how "art" and "ethnographic" objects are interpreted, valued and collected in the future.

\section{Acknowledgements}

My thoughts have been greatly influenced by a series of events that took place prior to the writing of this paper in 2006. In particular two major exhibition programmes played an important part in enabling me to articulate my internal arguments regarding the classification of high art and low art. The SHISHA programme ArtSouthAsia, held across several venues in the Northwest of England in 2002, was a major revelation and my first experience of seeing rural and urban arts from South Asia displayed and interpreted together. Secondly, the 3rd Fukuoka Asian Art Triennale hosted by Blackburn Museum and Art Gallery in the Northwest of England in 2006 allowed me to question my own assumptions regarding the type of objects historically collected by the Ethnology department and helped to shape my understanding of the department's future collecting priorities. Finally, I travelled to Pakistan, Bangladesh and Sri Lanka in 2005 as part of an Arts Council England professional development programme. The lively and often challenging conversations with colleagues in those countries regarding the classification of art and artists and the colonial legacies of the language we unconsciously use to define and separate practice and practitioners has had a direct impact on this paper.

Finally I would like to thank Dr Stephen P. Huyler who introduced me to Sonabai Rajawar's work and who made the commissioning of work and the visit to her home possible.

\section{Illustrations}

Figure 1: View of temporary exhibition space, Walker Art Gallery, Courtesy of National Museums Liverpool, p.5.

Figure 2: View of Buddhist display, World Museum, Courtesy of National Museums Liverpool, p.5.

Figure 3: 2005, Sonabai Rajawar, Photograph by Nick Gordon, p.8.

Figure 4: 2003, Sonabai Rajawar, Chherta Festival with Krishna Ca. (Clay, cow dung, straw, pigment), Photograph by Nick Gordon, p.8.

Figure 5: 2005, Decorated doorway, Puhputra, Chhattisgarh, India, Photograph by Nick Gordon, p.9. 
Figure 6: 2005, Atma Das Manikpuri, Photographyby Nick Gordon, p.10.

Figure 7: 2005, Atma Das Manikpuri, Elephant of Many Parts, (Clay, cow dung, straw, pigment). Photograph by Nick Gordon, p.11.

Figure 8: 2005, Montu Chitrakar, Courtesy of Minhazz Majumdar, p.13.

Figure 9: 2007, Pushpa Kumari, Courtesy of Minhazz Majumdar, p.14.

Figure 10: 2007, Pushpa Kumari ,Phases of the Moon, (Paper, ink), Courtesy of National Museums Liverpool, p.14.

Figure 11: 2007, Pushpa Kumari, Untitled, (Paper, ink) Courtesy of National Museums Liverpool, p.15.

Figure 12: 2002, Adeela Suleman, Salma, Sitara and Sisters - Motorcycle Workshop, (Mixed media), Courtesy of Adeela Suleman, p.16.

Figure 13: 2002, Adeela Suleman, Salma, Sitara and Sisters - Motorcycle Workshop (detail), (Mixed media) Courtesy of Adeela Suleman, p.17.

Figure 14: 2002, Adeela Suleman, Salma, Sitara and Sisters - Motorcycle Workshop (Helmet detail), Mixed Media, Courtesy of Adeela Suleman, p.17.

Figure 15: 2005, Truck decoration workshop, Karachi, Pakistan, Photograph by Emma Martin p.18.

\section{Bibliography}

Clifford, J., 1988. The predicament of culture: twentieth-century ethnography, literature and art.

Berkeley: University of California Press.

Clifford, J. \& Marcus, G. eds., 1986. Writing cultures: the politics and poetics of ethnography. Berkeley: University of California Press.

Dadi, I., 2006. Imagining south Asian craft under modernity. In Holt, J. et al., eds. Mapping artsouthasia. Manchester: Shisha p. 131-139.

Hashmi, S., 2001. Salma, sitara and sisters - motorcycle workshop. [postcard] Holt, J. et al., eds., 2006. Mapping artsouthasia. Manchester: Shisha.

Jain, J. ed., 1998. Other masters: five contemporary folk and tribal artists of India. New Delhi: Crafts Museum and The Handicrafts and Handlooms Exports Corporation of Indian Ltd.

Majumdar, M., 2006. Transforming tradition. Raw vision, 54(1), p.52-57. 
Rangasamy, J., 2006. I think therefore you are: a reflection on the curatorial challenges behind artsouthasia. In Holt, J. et al., eds. Mapping artsouthasia. Manchester: Shisha p. 31-39. Rangasamy, J. et al., eds., 2002. Artsouthasia. Manchester: Shisha.

Igarashi, R. ed., 2005. The 3rd fukuoka asian art triennale 2005. Fukuoka: Fukuoka Asian Art Museum.

Schneider, A. \& Wright, C. eds., 2006. Contemporary art and anthropology. Oxford: Berg.

Sheikh, G., 2006. Sites of art: other sites, other locations. Some aspects of visual cultures in India. In Holt, J. et al., eds. Mapping artsouthasia. Manchester: Shisha p. 41-53. 